\title{
El uso de Google Art \& Culture como apoyo en una asignatura de la Licenciatura en Psicología
}

\section{Google Art \& Culture supporting a subject in Psychology's Bachelor}

\section{Ingrid Marissa Cabrera Zamora ${ }^{1}$}

\begin{abstract}
Resumen
Se reporta la implementación de una actividad con el uso de la herramienta Google Art \& Culture con alumnos de primer semestre, del Sistema de Universidad Abierta, en la Licenciatura en Psicología, de la Facultad de Psicología de la UNAM. La actividad implicó la organización en dos fases: en la primera se utilizó la Unidad 3 correspondiente al Modelo Psicoanalítico, de la asignatura "Modelos en Psicología Clínica" para identificar las premisas, autores y conceptos. La segunda fase implicó el uso de Google Art \& Culture para elegir imágenes, videos y notas periodísticas con la finalidad de representar e identificar los contenidos teóricos. La actividad se realizó durante los semestres 2017-1 y 2018-1 participando, de forma voluntaria, un total de 14 alumnos. Los resultados indican el uso de elementos visuales como fotografías y videos sugeridos de la galería del Freud Museum London y del Sigmund Freud Museum que permiten, a los estudiantes, identificar premisas y conceptos representativos del modelo psicoanalítico, como son: la fotografía de Sigmund Freud, la fotografía de Carl Jung, el estudio de Freud, el diván psicoanalítico de Freud y el Escritorio de Freud. Finalmente, esta experiencia permite conocer una herramienta para reforzar el aprendizaje de los alumnos y difundir nuevos estudios, con el apoyo de las TIC, a los contenidos curriculares para fomentar la investigación en el Sistema de Universidad Abierta.
\end{abstract}

\footnotetext{
${ }^{1}$ Ingrid Marissa Cabrera Zamora. Docente de Asignatura en la Facultad de Psicología de la Universidad Nacional Autónoma de México. Es licenciada en Psicología por la Facultad de Psicología de la UNAM y Maestra en Educación, con Acentuación en Educación Media Superior, por la Universidad Virtual del ITESM. Correo electrónico: marissa@unam.mx
}

ID: http://orcid.org/0000-0003-3156-7440 
RECIE. Revista Electrónica Científica de Investigación Educativa Vol. 4, núm. 2, enero-diciembre 2019, pp. 1189-1199.

\title{
Palabras clave
}

Educación universitaria, educación y tecnología, recursos didácticos, enseñanza de la psicología.

\begin{abstract}
The activity reports the use of Google Art \& Culture in students, of the first semester; in the Open University System in Psychology's Faculty at UNAM. This activity involved the organization in two phases: the first one used the topic Psychoanalytic Model, in the subject "Models in Clinical Psychology" to identify the ideas, authors, and concepts. The second phase involved the use of the site Google Art \& Culture as a tool that supports the knowledge of the first phase, in which the students chose images, videos, journalistic notes referring to the psychoanalytic model, in order to represent and identify the theoretical contents. The activity has been made during the semesters $2017-$ 1 and 2018-1; the activity was done by 14 students voluntary. The results show the use of visual elements, such as photographs and videos, suggested by the gallery of the Freud Museum London and the Sigmund Freud Museum allow the students to identify ideas and representative concepts of the psychoanalytic model, for example: the photography of Sigmund Freud, the photography of Carl Jung, Freud's Study, Freud's Psychoanalytic Couch and the Freud's Desk. Finally, this experience allows knowing a tool to reinforce the learning of the students and to spread new studies in the support with ICT to curricular contents and doing investigation in the Open University System.
\end{abstract}

\section{Keywords}

University education, education and technology, teaching resources, teaching of psychology.

\section{Introducción}

En este documento se reporta la actividad realizada, durante dos semestres, con alumnos de primer semestre de la Licenciatura en Psicología. La propuesta surge a partir de la elaboración de un trabajo final para el curso denominado "Nuevos Aportes del Museo Virtual en el Marco de la Educación a lo largo de la Vida". Este curso se impartió durante el periodo intersemestral 2016-2 (correspondiente a junio de 2016) en la Facultad de Filosofía y Letras de la Universidad Nacional Autónoma de México por parte de la Dirección General de Administración del Personal Académico (DGAPA). 
El objetivo del curso fue la revisión del museo como una herramienta de apoyo didáctico a los contenidos de las asignaturas de nivel medio superior y superior. El curso conto con una duración de 40 horas, organizadas en actividades presenciales y a distancia. Respecto a los contenidos revisados, se abordó la concepción de museo, las principales funciones del museo, la concepción tradicional y moderna del museo y los museos virtuales.

\section{Concepciones del Museo}

Algunas de las definiciones para el museo son las propuestas por Tait (1989, citado por Pastor Homs, 2004) que indica que son llamados casas de tesoros o palacios de descubrimientos. Silva Moreno (2013) indica que "para conocer y adentrarse al mundo de los museos (sus colecciones, pinturas, arquitectura, exposiciones, etc.) no es necesario ser experto en arte o historia. Los museos y las piezas que albergan tienen la capacidad de despertar en el ser humano emociones, sensaciones, pensamientos y reflexiones" (p. 23).

Las funciones principales del museo son "coleccionar, conservar, investigar, exhibir y educar" (Alfageme González y Martínez Valcárcel, 2007, p. 4); una de las más importantes es la educativa. La fuente que da vida a los museos son sus visitantes, el museo permite el aprendizaje de manera permanente, a lo largo de toda la vida y en cualquier momento de ésta (Silva Moreno, 2016).

Las responsabilidades de un museo son variadas, en un inicio se enfocaban a conservar, custodiar y/o exponer diferentes objetos que albergaban. Actualmente las funciones del museo se han ampliado, implicando elementos de comunicación, información así como la realización de actividades educativas para el público que los visita.

Museos Virtuales

Silva Moreno (2013) indica que "los museos virtuales tienen el potencial de dar un nuevo significado a la relación entre grupos, personas y comunidades, a través de la tecnología que utilizan como el caso de internet, esta nueva idea permite que el museo se enfoque en el humano y en su participación dentro del museo virtual" (Teather, 1998 citado en Sabbatini, 2003).

El museo virtual es una colección de objetos digitales lógicamente relacionados..." (Sabbatini, 2003, citado en Silva Moreno, 2013). Esto implica que es un conjunto de piezas digitalizadas, pero también es un medio de información y educación que facilita el acceso a más personas con apoyo de la virtualidad. "Esto permitió la posibilidad de que su influencia no sólo se limitara al lugar donde se encontraba el 
objeto, también el conocimiento debía superar el espacio físico del museo (Silva Moreno, 2013, p. 76).

Silva Moreno (2013) indica que el museo virtual puede ofrecer recursos educativos a las personas como: las exposiciones virtuales, actividades en línea, materiales educativos para imprimir, oportunidades para interactuar con otros usuarios y con expertos, proporcionar información detallada acerca del museo y sus recursos, así como permitir a los usuarios participar en línea. Aunado a ello, el utilizar las redes sociales por medio de la difusión de los museos, elementos de interacción e información. Uno de los recursos que permite ejemplificar estos recursos del museo virtual es Google Art \& Culture.

\section{Google Art \& Culture}

De acuerdo a Silva Moreno (2013) el patrimonio cultural, material, natural e inmaterial son recursos irremplazables para el mundo. En el caso de los museos virtuales, gracias a la realidad virtual se logra "recopilar las obras alejadas geográficamente" (Bellido Gant, 2001, p. 119) y reunirlas en proyectos como Google Art \& Culture (anteriormente llamado Google Art Project).

“Google Art \& Culture es uno de los múltiples servicios que ofrecen la suite de Google, encargado de seleccionar los museos más importantes del mundo, digitalizarlos, recopilar información de las piezas, artistas, así como del propio museo". (Silva Moreno, 2013, p. 95).

Google Art \& Culture es un sitio web que pertenece al Instituto Cultural de Google. Se encarga de presentar una recopilación de imágenes, en alta resolución, de obras de arte expuestas en varios museos del mundo. Permite también un recorrido virtual por las galerías en las que se encuentran. El proyecto está a disposición del público desde el 1 de febrero de 2011, se inició con 1061 obras de 17 museos (Silva Moreno, 2013). La función de exploración de los museos se sirve de la misma tecnología utilizada por Google Street View. El 17 de julio de 2016, el proyecto se relanzó como Google Arts \& Culture, el cual incluye una aplicación móvil que permite acceder a los contenidos de más de mil museos en 70 países. (Google Arts \& Culture, 2018).

Considerando la oferta de museos localizada en Google Art \& Culture, se realizó la búsqueda de aquellos museos virtuales que tenían una relación con personajes representativos de la Psicología. La oferta es limitada, y los localizados fueron los que se describen brevemente:

El Freud Museum London (Museo de Freud, localizado en Londres). El Freud Museum London fue el hogar de Sigmund Freud y su familia después de la invasión nazi. Esta casa fue el centro de reunión familiar hasta la muerte 
de Anna Freud, la hija menor de Sigmund. La pieza central de este museo es el estudio de Freud, el cuál ha sido conservado tal como estaba cuando Freud vivía. Como museo virtual realiza la organización de programas de investigación y publicaciones, así como seminarios, conferencias y visitas especiales al museo (Freud Museum London, 2018).

El Freud Museum London puede considerarse un museo virtual por la organización que presenta con apoyo de la tecnología (página en internet) así como la difusión y uso de diversas redes sociales. En Google Art \& Culture, el espacio asignado a este museo presenta un acervo importante, tanto profesional como personal, de los últimos años de vida de Sigmund Freud. Se vislumbra desde su estudio, donde el diván es una de las imágenes más representativas de la colección, hasta bocetos, notas, fotografías familiares y artículos de periódicos y revistas (Freud Museum London, 2018).

Sigmund Freud Museum (en español se conoce como Casa Museo Freud localizado en Viena). La Casa Museo Freud (Viena) es una antigua casa donde vivió Sigmund Freud y su familia, previo a la invasión nazi (entre 1891 y 1938 aproximadamente). En la actualidad alberga un museo (Sigmund Freud Museum - Wien), una biblioteca especializada de la obra de Freud y del psicoanálisis (Sigmund-Freud-Haus-Bibliothek), el archivo Freud, con una apreciable colección de documentos históricos, cartas y certificados (Sigmund-Freud-Archiv), así como dependencias de la secretaría de la Sociedad Sigmund Freud (Sigmund Freud Gesellschaft). (Sigmund Freud Museum, 2018).

El 7 de septiembre de 2016, el Museo Sigmund Freud de Viena anunció una importante ampliación de sus instalaciones hasta el año 2020, para atender mejor la creciente demanda de visitantes de todo el mundo. En Google Art \& Culture se presenta un espacio para este museo donde presenta un acervo importante de sus inicios como profesionista, permite visualizar la relación con sus colegas por medio de fotos institucionales (por ejemplo con Carl Jung). (Sigmund Freud Museum, 2018).

\section{Perfil del estudiante del SUA}

En la Facultad de Psicología de la Universidad Nacional Autónoma de México se imparte la Licenciatura en Psicología en dos modalidades: sistema escolarizado y sistema de universidad abierta. El Sistema de Universidad Abierta (SUA) es una modalidad educativa que permite a los estudiantes realizar otras actividades y estudiar al mismo tiempo, lo que implica que el estudiante posea y/o desarrolle habilidades para el estudio independiente (administración del tiempo, estrategias de aprendizaje, una excelente comprensión de lectura, una buena capacidad de redacción, así como un buen 
manejo de herramientas de Internet, etc.). (SUA, 2018). Aunado a ello, se tiene como apoyo el uso de recursos tecnológicos para la asesoría, evaluación y seguimiento de alumnos como son el correo electrónico, la plataforma educativa Moodle, sitios web desarrollado por los profesores, grupos interactivos en redes sociales o uso de chat virtuales como Skype, Hangout o Whastapp.

\section{Objetivo}

El propósito de la actividad considera la asignatura "Modelos en Psicología Clínica", en los semestres 2017-1 y 2018-1 de la Licenciatura en Psicología del Sistema de Universidad Abierta de la Facultad de Psicología de la UNAM y el uso de la herramienta Google Art \& Culture para representar los contenidos teóricos adquiridos en la unidad del Modelo Psicoanalítico para relacionar y reforzar los conocimientos adquiridos. El objetivo es identificar, en los alumnos que realizaron la actividad propuesta, los recursos (imágenes, fotografías, videos, notas periodísticas) seleccionados con mayor frecuencia así como la opinión de la actividad por medio de la difusión del trabajo con otros compañeros con apoyo de la red social denominada Google +.

\section{Metodología}

La actividad es de tipo voluntario, se contó con la participación de 14 alumnos, inscritos en la asignatura "Modelos en Psicología Clínica" de primer semestre, de los cuáles 9 pertenecían al grupo 9115 correspondiente al semestre 2017-1 y 5 del grupo 9116 correspondiente al semestre 2018-1.

La actividad se organizó en dos fases: la primera es de índole teórica, que consistió en que los alumnos realizaron una investigación del tema "Modelo Psicoanalítico" de la asignatura "Modelos en Psicología Clínica" y se solicitaba la entrega de un documento escrito. Los alumnos consideraron los siguientes temas para la elaboración de la actividad: autores representativos del modelo; conceptos claves; y métodos de atención representativos.

La segunda fase de la actividad consistió en la incorporación de Google Arts \& Culture, a partir del contenido investigado. Se solicitó a los alumnos ingresar al servicio Google Arts \& Culture y generar una "Colección" (es decir, un espacio que permite "agregar" imágenes, videos, fotografías de los museos registrados en el servicio). El alumno selecciona entre 10 y 20 elementos de los museos (Freud Museum London y Sigmund Freud Museum). Este es un producto entregado de forma digital en un espacio en común denominado Google + (Google Plus). Para esta actividad, el espacio está disponible en el siguiente enlace: 
https://plus.google.com/u/0/communities/109914671689465877859 y permite compartir los recursos seleccionados por cada alumno con sus compañeros de grupo.

\section{Resultados}

Entre los resultados se identifican las imágenes de mayor elección por parte de los alumnos, así como los principales comentarios para presentar sus colecciones en la red social Google +. Los resultados se presentan en la Tabla 1:

Tabla 1. Frecuencia de las imágenes seleccionadas

\begin{tabular}{|l|c|}
\hline \multicolumn{1}{|c|}{ Imagen } & Frecuencia \\
\hline Sigmund Freud, 1938 & 8 \\
\hline Carl Gustav Jung & 7 \\
\hline Freud's desk & 7 \\
\hline Sketch of Sigmund Freud by Salvador Dali & 6 \\
\hline Freud's psychoanalytic couch & 6 \\
\hline Freud's study at the Freud Museum London & 6 \\
\hline Jean Martin Charcot & 6 \\
\hline Newspaper reaction to Freud's presence in England & 6 \\
\hline Une leçon clinique du Dr. Charcot à la Salpêtrière & 5 \\
\hline $\begin{array}{l}\text { Letter from Sigmund Freud to the mother of a } \\
\text { homosexual man }\end{array}$ & 5 \\
\hline Part of 2nd Psychatrical Hospital & 5 \\
\hline Sigmund and Anna Freud on their way into exile & 5 \\
\hline Sigmund Freud with his father & \\
\hline
\end{tabular}

Entre los comentarios realizados por los alumnos ante la experiencia de utilizar la herramienta Google Art \& Culture como apoyo a la unidad, se pueden retomar los que implican contenidos teóricos y su opinión ante el uso de la herramienta que era desconocida para la mayoría de ellos. Los resultados se presentan en la Tabla 2.

Tabla 2. Comentarios de los alumnos ante la experiencia de usar Google Art \& Culture.

\begin{tabular}{|l|l|}
\hline Alumno 1. K. M. & $\begin{array}{l}\text { "La herramienta Google Arts \& Culture representa una } \\
\text { opción innovadora para acercar la cultura a cualquier } \\
\text { persona en el mundo. En este caso, el recorrido virtual a } \\
\text { los museos Freud Museum London y Sigmund Freud }\end{array}$ \\
\hline
\end{tabular}

El uso de Google Art \& Culture como apoyo en una asignatura... 
RECIE. Revista Electrónica Científica de Investigación Educativa Vol. 4, núm. 2, enero-diciembre 2019, pp. 1189-1199.

\begin{tabular}{|l|l|}
\hline & $\begin{array}{l}\text { Museum sirvió para complementar y asimilar de mejor } \\
\text { forma los conocimientos adquiridos sobre la vida de } \\
\text { Sigmund Freud y el desarrollo del psicoanálisis". }\end{array}$ \\
\hline Alumno 2. M. V. & $\begin{array}{l}\text { "La colección permite visualizar los conceptos más } \\
\text { significativos del enfoque psicoanalítico como son: el } \\
\text { método de asociación libre, la fuerte lucha entre el yo y } \\
\text { el ello, complejo de Edipo y la carga del ámbito sexual } \\
\text { que Freud manejaba. Así mismo, permite recordar la } \\
\text { historia de vida más cruel que pudo haber vivido como } \\
\text { fue la huida de Freud y su familia por la llegada de los } \\
\text { Nazis". }\end{array}$ \\
\hline Alumno 3. M. Z. & $\begin{array}{l}\text { "A través de las fotos nos permite adentrarnos a la vida } \\
\text { y obra de Sigmund Freud el padre del Psicoanálisis, que } \\
\text { nos permite conocer el porqué de dicha tradición, así } \\
\text { como su génesis mediante la represión sexual, en virtud } \\
\text { de la connotación histórica y cultural de la época". }\end{array}$ \\
\hline Alumno 4. D. P. & $\begin{array}{l}\text { "Personalmente considero que Freud es uno de los } \\
\text { personajes más importantes en la historia de la } \\
\text { psicología, ya que su legado se sigue viendo reflejado aún } \\
\text { en la actualidad. Personalmente me agrado mucho la } \\
\text { actividad, ya que nunca había utilizado esta herramienta, } \\
\text { la cual me permitió trasladarme a otro sitio a través del } \\
\text { uso de las TIC'S". }\end{array}$ \\
\hline Alumno 5. M. H. & $\begin{array}{l}\text { "Me gustó mucho la actividad por algunas razones que } \\
\text { quiero mencionar: no conocía esta herramienta de } \\
\text { Google y me pareció muy interesante, pues se puede } \\
\text { recorrer de manera virtual diferentes espacios (museos, } \\
\text { galerías, colecciones) alrededor del mundo y además } \\
\text { seleccionar las imágenes y datos favoritos para verlos } \\
\text { una y otra vez; siempre es agradable "ponerle cara" a lo } \\
\text { que se lee, a las personas, a las cartas, a los momentos } \\
\text { que se mencionan en las investigaciones; ver el } \\
\text { escritorio de Freud tan parecido como se muestra en la } \\
\text { película, me pareció de muy buen gusto. En fin, me } \\
\text { pareció una buena manera de cerrar el tema de Freud". }\end{array}$ \\
\hline $\begin{array}{l}\text { apl recorrer estas imágenes me permitió reforzar lo } \\
\text { aprendido en la unidad. Recordar y conocer físicamente } \\
\text { fue satisfactoria para recordar la importancia social en }\end{array}$ \\
\hline
\end{tabular}




\begin{tabular}{|l|l|}
\hline el trabajo de, incluso, las mentes más brillantes. \\
Recordar partes de la biografía de Freud, lo cual siempre \\
ayuda a imaginar parte del por qué un hombre construye \\
el universo simbólico que construye al revelar su punto \\
de enunciación físico y social. Así mismo, al ver las obras \\
plásticas podemos percatarnos de cómo no solo el \\
psicoanálisis inspiró a un gran número de artistas e \\
intelectuales, el arte también impactó de manera \\
profunda en el quehacer psicoanalítico a través de \\
analogías".
\end{tabular}

\section{Conclusiones}

Esta actividad permitió establecer que se cuentan con pocos antecedentes teóricos y de investigación respecto al uso de los museos como apoyo a los contenidos curriculares en las asignaturas del SUA, así como pocos antecedentes en el uso de herramientas (como Google Art \& Culture) en la Licenciatura en Psicología. Esto impacta en la búsqueda y selección de recursos digitales y herramientas TIC que permitan, a la modalidad de sistema abierto, el reforzamiento y adquisición de contenidos curriculares de diversas formas.

Respecto a la asignatura se invita a los docentes a realizar búsquedas de otros museos virtuales que presenten información digitalizada, con contenidos de otros modelos revisados en la asignatura elegida, o bien de otras asignaturas. Para el caso de la asignatura "Modelos en Psicología Clínica" se requiere la búsqueda de ejemplos que refuercen los contenidos del Modelo Sistémico, el Modelo Humanista por mencionar algunos. La temática psicológica propiamente puede no ser atractiva, inicialmente, para un museo. En el caso de Freud, su relevancia social, cultura, y en el campo psicológico es tal que sus museos han adquirido una fama importante, logrando que el Freud Museum London difunda sus eventos e fomente interacción con usuarios por medios presenciales y virtuales, así como la actualización del acervo que se tiene en Google Art \& Culture y una creciente incorporación de seguidores en redes sociales como Facebook, Twitter e Instagram.

Respecto a comentarios realizados por los alumnos, se puede indicar que retoman el acceso a estos espacios que les eran desconocidos; así como la selección de imágenes alusivas que permiten tener una representación visual del contenidos teórico revisado; por ejemplo el diván es representativo de la técnica que se utiliza en el modelo psicoanalítico y los 14 voluntarios lo seleccionan en alguno de los diversos recursos que se tiene en los dos museos virtuales sugeridos.

El uso de Google Art \& Culture como apoyo en una asignatura... 
Cabe destacar también la elección de fotografías familiares, que permite indagar sobre la curiosidad e inquietud de conocer, más allá del mismo modelo, una cuestión sobre el interés, fundamentación o motivos de plantear un modelo; y cómo esto implica la creación y establecimiento de conceptos como los mecanismos de defensa, las instancias psíquicas, etc. Si bien las fotografías son llamativas ( 3 alumnos eligen aquella donde Freud aparece retratado con su hija Anna), también se presentan los objetos personales más íntimos (como escritos de Freud en hoja amarilla, la foto de su dentadura, un retrato realizado y firmado por Salvador Dalí). Con esto se puede retomar la importancia del museo como una entidad de aprendizaje permanente, de acceso libre y, gracias a la tecnología, el acceso a espacios con una localización e idioma diferentes. Y la forma en que se adquieren conocimientos para una población como el SUA, cuya interacción e independencia demanda el uso de propuestas, actividades y herramientas como las utilizadas.

Por último, y no menos importante, que se extienda este interés de investigación a otros docentes para compartir y considerar la herramienta como un elemento complementario del Sistema de Universidad Abierta. No solo Google Art \& Culture, sino buscar y retomar alguno de los elementos que se ofrecen de forma libre para fomentar el uso digital y reforzar los aprendizajes adquiridos en los diversos sistemas y modalidades de la Licenciatura en Psicología.

\section{Referencias}

Alfageme González, Ma. B. y Martínez Valcárcel, N. (2007, Noviembre). Un Modelo Pedagógico en un Contexto No Formal: El Museo. Archivos Analíticos de Políticas Educativas, Vol. 15(21), 1-19. Recuperado el 04 de mayo de 2018, de http://epaa.asu.edu/ojs/article/view/69

Alonso Fernández, L. (2001). Museología y museografía. (2a edición). España: Ediciones del Serbal.

Facultad de Psicología. Página Principal. Recuperado el 20 de mayo de 2018 en http://www.psicologia.unam.mx

Freud Museum London. Recuperado el 20 de mayo de 2018 en https://www.freud.org.uk/

Google Art \& Culture. Recuperado el 20 de mayo de 2018 en https://www.google.com/culturalinstitute/beta/?hl=es

Pastor Homs, Ma. I. (2004). Pedagogía Museística: Nuevas perspectivas y tendencias actuales. España: Ariel Patrimonio. 
Sabbatini, M. (2003). Centros de Ciencia y Museos Científicos Virtuales: Teoría y Práctica. Teoría de la Educación: Educación y Cultura en la Sociedad de la Información, (4).

Sigmund Freud Museum. Recuperado el 10 de mayo de 2018 en http://www.freud-museum.at/en/

Silva Moreno, M. C. A. (2013). La Didáctica del Museo Virtual, Una Propuesta de Educación a lo Largo de la Vida. Tesis de Licenciatura. Facultad de Filosofía y Letras, UNAM: México. Recuperado en: http://132.248.9.195/ptd2013/abril/301613929/301613929.pdf

Sistema de Universidad Abierta de la Facultad de Psicología. Página Principal. Recuperado el 10 de mayo de 2018 en http://sua.psicologia.unam.mx/ 
RECIE. Revista Electrónica Científica de Investigación Educativa Vol. 4, núm. 2, enero-diciembre 2019, pp. 1189-1199. 